\title{
THE IMPACT OF CODE-SWITCHING AND CODE MIXING IN ADVERTISING
}

\author{
* Ms Sumitra Biswal
}

\begin{abstract}
Code switching and other related language use phenomenon occurs in all linguistic situations, monolingual or bilingual situations. Code switching in a monolingual situation indicates the Diglossic switching and dialectal switching .Diglossic code switching means mixing or shifting of codes from standard variety to a low variety or vice versa depending upon the demands of some of social and psychological situations. Sometimes, a person who knows more than one dialects uses different codes. A person who belongs to one particular dialect may use a standard code in formal situation or with his friends. At the same time, he may change from one code to another assuming that the hearer also knows the change in the code. In a bilingual situation also code switching occurs. A person who knows two languages may know the cultural background of both the languages, and sometimes becomes proficient in both the languages and thereby he adopts code switching during language.
\end{abstract}

This Article shows that consumers' language attitudes are an important consideration when it comes to writing ads. Consumers attach certain associations to different languages. These associations then influence their attitudes toward ads that are written in that language.

The research shows that even ads that are written in two languages like "Hinglish" can awaken such associations, and that the same slogan can result in different reactions depending on the language that draws the most attention. The article also underscores the importance of code-switching and code mixing in advertising. Code-switching, far from being an isolated practice, is used frequently in the media and in everyday life. For consumers.

This research highlights the importance of language in everyday life, For marketers, the importance of language and consumers' attitudes towards the language used in advertising. This is particularly relevant for advertisers targeting bilingual markets. The article discussed here is part of the authors' broader investigation of code-switching \& code mixing in advertising. By studying this linguistic practice in depth, consumer researchers will gain insight into bilingual consumers' minds, motivations, and actions.

* Srusti Academy of Management Patia, Chandaka Industrial Estate, Bhubaneswar-751031, Odisha, India Email : Sumitra.biswal@gmail.com Mob : 09938435532 


\section{Code Switching and Code mixing:}

\section{A Conceptual Overview}

Terms in sociolinguistics for language and especially speech that draws to differing extents on at least two languages combined in different ways, as when an oriya /English bilingual say: This morning: mu fish buy karibaku market jauchi.). A code may be a language or a variety or style of a language; the term code mixing emphasizes hybridization, and the term codeswitching emphasizes movement from one language to another. Mixing and switching probably occurs to some extent in the speech of all bilinguals, so that there is a sense in which a person capable of using two languages.

Consumer researchers have recently investigated the effect of mixing languages in ads -that is, the implications of using "Hinglish " in advertising. Linguists call this practice "code-switching." Code-switching is often used in media targeting ethnic minorities like Hispanics in the U.S, but it is not unique to Spanglish. Code-switching happens in most bilingual communities; for example, in Singapore, where English is peppered with Malay and other languages, the mixture is called "Singlish."

In a recent article, David Luna and Laura Peracchio looked at several advertising slogans that use code-switching. They found that there is more than meets the eye when it comes to language use. Different languages mean different things to their users. For example, many Hispanics in the U.S. are bilingual, so they could use either Spanish or English interchangeably. However, they perceive English as the language of power and dominance. Spanish can be associated with a feeling of inferiority and discrimination.
Consequently, when a code-switched ad draws attention to its English portion, Hinglish or mixing with any local language responses tend to be more favorable than when the ad draws attention to its English portion. Interestingly, consumers seem to pay more attention to the language that is less used in the ad, just because it stands out from the rest of the ad.

\section{Example of Code-switching:}

Hey there how are you?

Am fine, long time no see, aur bolo kya haal chal? Sab thik hai yaar, bas am a little busy these days.

Okay, how's your worklife?

Cool yaar, sab thik hai, acha hai

If I need to translate it, it will read something like this.

Hey there, how are you?

Am fine, long time no see, so what's up?

Everything is fine, but I am a little busy these days.

Okay, how's your work life?

Cool buddy, everything is fine

\section{Example of Code Mixing}

Yeh train ka time change ho gaya hai kya? If you notice in this particular sentence there is mix of Hindi and English.

\section{General code}

The term code refers to speech varieties or dialects in a language or even languages. This is widely used in the field of linguistics, and it is studied always in a social context. Further, it is a signal used by the speaker to convey some messages. The term 'code switching'. means switching from one language variety to another when the situation demands. 
There are two other aspects related to code switching. They are code mixing and shifting. Code switching is known as switching from one code to another. Code mixing means mixing of two different codes within a sentence. Code shifting is another variety which takes place at phrasal level.

\section{Code switching can be both situational and metaphorical.}

Situational code switching occurs when the codes are used depending upon the situations. When a situation of a speaker changes, the codes used in them also changes. Here, a change of topic requires a change of language. The process of changing the codes has connections with the social value and status of speakers. Since, they are deciding the codes to be selected. Code mixing occurs when the speakers use two or more languages together and mix them in a single utterance or in the communicative act.

Code switching and other related language use phenomenon occurs in all linguistic situations, monolingual or bilingual situations. Code switching in a monolingual situation indicates the Diglossic switching and Dialectal switching .Diglossic code switching means mixing or shifting of codes from standard variety to a low variety or vice versa depending upon the demands of some of social and psychological situations.
For example, a person speaking to an educated person or to an honored person in the society, he uses a standard variety. At the same time, when he speaks to the person who is socially lower in status' he uses a low variety. But, when he speaks with his family friends or other related persons, he mixes both the high and low varieties of the languages. In a casual conversational situation, there will be a mixture of both the codes.

Sometimes, a person who knows more than one dialect uses different codes. A person who belongs to one particular dialect may use a standard code in formal situation or with his friends. At the same time. he may change from one code to another assuming that the hearer also knows the change in the code.

In a bilingual situation also code switching occurs. A person who knows two languages may know the cultural background of both the languages. and sometimes becomes proficient in both the languages and thereby he adopts code switching during language use.

For example, an Oriya speaking person who has wider exposure to English then his mother tongue will be often switching to English from Oriya due to his proficiency or due to certain psychological reasons or motives.

Code switching is also possible in a multilingual situation; when a speaker uses more then two languages, he often switches over from one to another and ends up in mixing of all the codes. This is common in multilingual countries like India. 


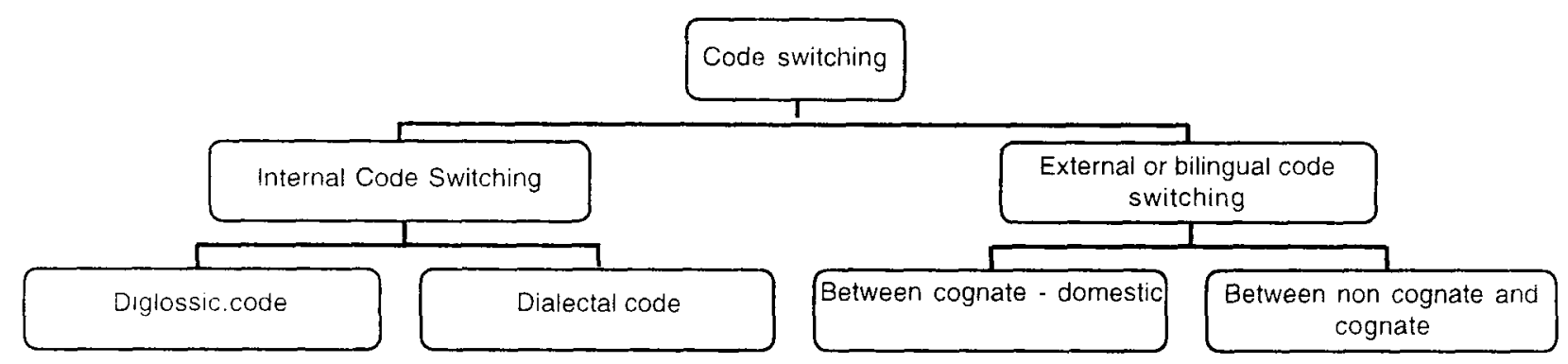

\section{Classification of code switching(fig-1)}

\section{Diglossic code}

Diglossic code switching is common in casual conversation. From the data collected, it was obvious that the selected informants used the standard variety of the language in formal situation, and they use low variety of the language in a nonformai situation. They use the standard variety or codes when they speak to their consumers and with the managers. At the same time, in a casual context or with coworker or with family, they use either the standard variety or low variety of a language

Code switching takes place in other situation also. Especially. when the intormants were asked to narrate story, they were using the standard and the low varieties.

\section{Example 1}

When an informant was telling about the present political situation, he used the standard variety.

"It is the government duty to remake the law for the benefits of the people and to suit the developing trends of the nation. Advocates' agitation is illegal."

\section{Example 2}

Another informant when he was telling about an incident, he used the standard variety and low variety alternatively.

"Why the advocates agitate against the government seriously?! if the government remakes the law, their income will be decreased. So, they won't pull back their strike even if they were beaten by police"..

\section{Example 3}

An informant, when he was telling his day to day activities he used the standard as well as low variety items.

"Come on... how are you? When did you come from your village?"

All the words of the above mentioned example are low variety words.

Another informant, when he was talking with his neighbor has used only low variety.

Hi...come on...!

Where are you working?

Show me. What do you have in your bag?

In this way, the Diglossic codes were used by the informants. Some workers said that when they speak to their managers, unconsciously they switch over to low variety codes otherwise standard code occupies. 


\section{Dialectal code switching}

Dialectal code switching includes code mixing and code shifting. This type of variation takes place in a monolingual situation. From the data collected, it was found that some of the people were switching from one dialect to another dialect though they are bilinguals.

Sometimes, the informants manifest the switching behavior not only from one dialect to another dialect but also from one standard dialect to a social dialect or some time from a social dialect to the standard dialect.

For example:

From the data collected, it was evident that those who have migrated from Bengal District to Bhubaneswar and have been doing platform business use the language in such a way as:

"Have you seen my daughter who has come?!

She is studying at KIIT College!

I am telling with you only.

Why are you being silent?!"

\section{Dialectal code shifting}

Dialectal code shifting denotes a functional context in which a person makes alternate use of two or more dialectal codes.

Oriya dialectal code shifting is found in the speech of Bengali Oriya.For example,

"Where have you gone for a long time?!

Give money to my daughter.

Let her to come to good position by studying"

Ata din habe kuthaye gayache tumi?

In this dialect Ata din habe kuthaye gayache tumi?' which reflects a dialectal form of the Bengali and oriya. The reason for the mixed dialect varieties was also given by the informants they said that before migrating to Bhubaneswar, they did platform business at Baleswar, and Baripada (districts of Orissa)also; though their birth place was Calcutta.

\section{Code switching and ads}

When a code-switched ad draws attention to its English portion, bilingual responses tend to be more favorable towards the ad which draws attention to its code mixing and code switching portion. Interestingly, consumers seem to pay more attention to the language that is less used in the ad, just because it stands out from the rest of the ad. Recently Vodafone used the same strategy in Orissa instead of writing the punch line "Most of Now" they are writing in Oriya to attract the bilingual customers by writing the punch line "Kete khana kete kana". Airtel also always try to catch the emotional aspect the mother tongue of Orissa people using the Oriya terms in the ad.

Let's look at some TV commercials where the growing use of Hinglish cannot be ignored. Hinglish is deliberately used to make these more catchy.

In an ad for a certain shampoo. Priyanka

Chopra says:

C'mon girls, waqt hai shine karne ka!

Punch line for pepsi is:

Yehi hai right choice baby

Yeh dil maange more.

Coca Cola:

Thanda matlab coca cola.

Vicco Turmeric:

Vicco Turmeric, Nehi Cosmetic;

Vicco Turmeric Ayurvedic Cream.

Multinational companies advertising luxury goods abroad should consider advertising those goods in English, whereas ads for necessities might be more effective in local languages, according to a new study. Authors Aradhna Krishna (University of Michigan) and Rohini Ahluwalia (University of Minnesota) examined the role of language in advertisements in India. 
The results of their study indicate that multinational corporations marketing products to bilingual populations should pay special attention to languages. The participants' perceptions of ads changed significantly when different languages were used.

"We find that while the Hindi or Oriya (any local language) language is associated with "belongingness" (close, personal, friendly, family), English is associated with "sophistication" (global, cosmopolitan, urban. upper class).

Participants associated "belongingness" with necessities, such as detergent, and the researchers found that ads for detergent were more effective when the ads were partially or fully in Hindi or any other local language.

In contrast, when the product being marketed was a luxury item-chocolate in the case of this studyparticipants reacted more favorably to ads that were in English.

\section{Methodology}

The present study based on primary data. Data has been collected from 100 respondents in Bhubaneswar, Orissa. The informants are migrated from Bihar and Bengal (non Oriya). The respondents are administered a structured questionnaire and aiso some data collected by Indirectly supervising their communication with their friends, workers and family members.

Research questions:

1. How do you like to communicate with your co-workers, consumers, friends or relatives?

2. Give your ratings on proficiency of the language that you know.

3. What made you to mix the languages (Hindi \& English or Hindi \& Oriya) in different context?
4. Do you feel consumers are more attracted towards the use of code mixing and code switching rather than one formal or official language?

5. Do you feel the switching and mixing of languages creates love belongingness among people?

6. Do you feel English signifies sophistication?

\section{Research Objectives}

The objective of this study is to find out :

- How the code switching and code mixing occur in different language situations

- How it affects the behavior pattern of the persons in different context.

- How it creates love and belongingness towards a particular person or brand.

\section{Data Analysis}

Bilingual code switching includes simultaneous use of English, Oriya , Bengali, Bihari etc .For this study, Oriya \&Bengali business man and also consumers are taken in to consideration for code switching. It is not necessary that both the speaker and the hearer must know two languages. The second language may be acquired through many contexts. For example,

i) In the Second Language context,

ii) In the Business context

In the data collected for the study (fig1-4), the above two influence the language behavior of the speakers and create the context for bilingual code switching. In the present study, the data collected was sufficient enough to prove code shifting and code mixing strongly. Code shifting including the use of Oriya \& Bengali in the bilingual situation is also noted. 
The people who were migrated to Orissa from Calcutta fifteen years ago, and settled in Orissa They learned Oriya for various purposes. So, code mixing occurs spontaneously in their speeches, and sometimes they are not aware of it. They use some Oriya vocabulary items while they speak Bengali.

The informant told that she and her family migrated to Bhubaneswar fifteen years ago. So this kind of code mixing appears in their speech.

\section{Contexts and Language behaviors}

Language behavior varies from one domain to another. A person will adapt different varieties or codes and styles and keep switching over from one code to another depending upon the context.

A person's social intimacy, social relationship, social distance the situation of both the speaker and hearer, all play their roles in the language behaviour. The speaker is not selecting his own way or style in his language use, but the context determines the varieties according to the situations.

Informants during the Diglossic code switching, switch over from one variety to another. The varieties are standard and low varieties. They give reasons for their language behavior also. They use standard variety only in formal context. In some other context, they use low variety.Switching Behavior involving the use of dialectal varieties is not conditioned. They switch over from one dialect to another depending upon the hearer.Gererally in this study, it was observed that when the topic changes the codes also change.

\section{WITH CONSUMER}

\begin{tabular}{|c|c|c|c|c|c|}
\hline $\begin{array}{c}\text { No of } \\
\text { informants }\end{array}$ & context & $\begin{array}{c}\text { Types of } \\
\text { Hearers }\end{array}$ & Mother Tongue & $\begin{array}{c}\text { The Language } \\
\text { use in particular }\end{array}$ & \multicolumn{1}{|c|}{ Reason } \\
\hline $20 \%$ & Casual & Consumer & Oriya & English / Hindi & $\begin{array}{l}\text { Some Consumers } \\
\text { are Bengali }\end{array}$ \\
\hline $15 \%$ & Casual & Consumer & Oriya & Oriya & $\begin{array}{l}\text { Consumers are } \\
\text { Oriya }\end{array}$ \\
\hline $65 \%$ & Casual & Consumer & Oriya & Oriya \& English & $\begin{array}{l}\text { Normally code } \\
\text { mixing is found } \\
\text { in their speech } \\
\text { because of Oriya } \\
\text { influence. }\end{array}$ \\
\hline
\end{tabular}

(Fig-1. code switching among consumers)

In a Diglossic situation, it was found out that when the informants speak about their subject, they use either the standard variety or low variety. And in a bilingual situation, code switching occurs depending upon the topic. 


\section{WITH CO-WORKERS}

\begin{tabular}{|c|c|c|c|c|c|}
\hline $\begin{array}{c}\text { No of } \\
\text { informants }\end{array}$ & context & $\begin{array}{c}\text { Types of } \\
\text { Hearers }\end{array}$ & Mother Tongue & $\begin{array}{c}\text { The Language } \\
\text { use in particular }\end{array}$ & Reason \\
\hline $65 \%$ & Casual & Co-worker & Oriya & Oriya & No Reason \\
\hline $20 \%$ & Casual & Co-worker & Oriya & Oriya \& English & $\begin{array}{l}\text { Due to influence } \\
\text { of Co-worker }\end{array}$ \\
\hline $15 \%$ & Casual & Co-worker & Oriya & Oriya(Sambalpuri) & $\begin{array}{l}\text { Due to influence } \\
\text { of Sambalpuri } \\
\text { Oriya(Low } \\
\text { verityOriya) }\end{array}$ \\
\hline
\end{tabular}

(Fig-2. code switching among co-workers)

The data was collected from fifty informants whose mother tongue is Oriya. They use Oriya and Bengali alternatively in their day to day activities. $35 \%$ of informants were using Oriya and English alternatively or with mixing and shifting. When the reason was asked, they told the investigator that they migrated to Bhubaneswar 20 years back. Hence, they have proficiency in both the languages, and this might be the reason for mixing and shifting.

WITH THE FRIENDS

\begin{tabular}{|c|c|c|c|c|c|}
\hline $\begin{array}{c}\text { No of } \\
\text { informants }\end{array}$ & context & $\begin{array}{c}\text { Types of } \\
\text { Hearers }\end{array}$ & Mother Tongue & $\begin{array}{c}\text { The Language } \\
\text { use in particular }\end{array}$ & Reason \\
\hline $20 \%$ & Casual & Close Friends & Oriya & English & $\begin{array}{c}\text { Due to the } \\
\text { influence of } \\
\text { English }\end{array}$ \\
\hline $15 \%$ & Casual & Close Friends & Oriya & Oriya & No reason \\
\hline $65 \%$ & Casual & Close Friends & Oriya & Oriya \& English & Depending \\
\hline $65 \%$ & Casual & Close Friends & Oriya & English & On the situation \\
\hline $65 \%$ & Casual & Close Friends & Oriya & Oriya & $\begin{array}{c}\text { Whose mother } \\
\text { tongue is Oriya }\end{array}$ \\
\hline $65 \%$ & Casual & Close Friends & Oriya & Oriya \& English & $\begin{array}{c}\text { No Reason } \\
\text { Depending on } \\
\text { situation }\end{array}$ \\
\hline
\end{tabular}

(Fig-3. code switching among friends) 
$15 \%$ of the informants used only Oriya in their speech, and occasionally they mixed some Bengali lexical items. In their speech, only mixing was found, and shifting was not found. They told the investigator that they had less proficiency in Oriya as they have come to Bhubaneswar recently. This may be the reason for the lesser degree of code shifting in their speech.

\section{WITH THE FAMILY MEMBERS}

\begin{tabular}{|c|c|c|c|c|c|}
\hline $\begin{array}{c}\text { No of } \\
\text { informants }\end{array}$ & context & $\begin{array}{l}\text { Types of } \\
\text { Hearers }\end{array}$ & Mother Tongue & $\begin{array}{l}\text { The Language } \\
\text { use in particular }\end{array}$ & Reason \\
\hline $20 \%$ & Casual & Elders & Oriya & Sambalpuri Oriya & $\begin{array}{l}\text { They have much } \\
\text { proficiency in } \\
\text { Sambalpuri } \\
\text { Oriya (Low verity } \\
\text { oriya) }\end{array}$ \\
\hline $15 \%$ & Casual & Elders parent & Oriya & Oriya & $\begin{array}{l}\text { They have not } \\
\text { much proficiency } \\
\text { in others }\end{array}$ \\
\hline $65 \%$ & Casual & Elders parent & Oriya & Oriya \& English & $\begin{array}{l}\text { They have } \\
\text { proficiency in } \\
\text { both }\end{array}$ \\
\hline
\end{tabular}

Fig-4. code switching among family members

Informants use a type of code with their family members who are more informal, casual and simple. The informants speak Oriya within their family. Since, they were brought up in that way. With the friends, they use both the mother tongue and English. During their business time, they use English and Hindi languages alternatively.

\section{Findings}

Three different contexts of code switching are found in the present study are as follows:

\section{Specific}

Among the informants, three-fourth of them was platform shopkeepers, and they specifically use Hindi \& Oriya alternatively. They use the standard variety of language with the consumer and with their friends. Hence, occasionally they use low variety of language.

\section{Attracting the consumers}

In the data recorded without the informant's knowledge during business time, they use standard and low variety codes. Some times or often, they switch over from one dialect to another. And also, English-Oriya code switching occurs. They use both the languages to attract the consumers. 


\section{Circumstantial necessity}

Having Oriya as their mother tongue, the Oriya people who live in Orissa speak both Hindi \& English. Because they were doing business in order to thrive in their business, they happen to learn Hindi language in different contexts.

These variations are amply evident from the data collected. and the present study identified the following types of code switching. They are:

a. Word level code switching,

b. Syntactic level code switching,

c. Phrase level code switching.

d. Grammatical level code Switching.

The types of code switching behavior along with its setting were found out; bilingual code switching behaviors was also identified. This study also concentrates on the reasons for code switching, the context of code switching; various domains of code switching etc. and elaborate them. It has been strongly proved that the change of topic and the change of setting influence the language behavior and thus, they control the code switching process.

\section{Limitation of the Study}

During the interaction, information transfer brings shifts from one language to another, one dialect to another and from one variety to another depending upon the role of the speaker, and the occupation of the addressees and the existence of the situation. If the number or the informants were more. we could have studied the language use with regular mixing in a deeper and wider perspective.
This would have enabled us to provide evidence, and also helped us to give the conditions, the reasons and results of the data with adequate statistical figures. Since. this study is a small scale study; an attempt is made to see an overall way of code switching behavior and use of language of bilinguals in Bhubaneswar City. There is scope for a detailed study in the future.

\section{CONCLUSION}

In the data recorded without the informant's knowledge during business time, they use standard and low variety codes. Some times or often, they switch over from one dialect to another. And also, Oriya and Bengali code switching occurs. They use both the languages to attract the consumers. The authors also found that study participants responded favorably to mixedlanguage advertising, when words from both languages were found in the advertising slogans.

"Results of this experiment suggest that multinational corporations need to be more cognizant about language choices in global bilingual markets, and it would be ill advised for them to simply follow the choices that appear to be working for the local corporations," the authors conclude. 


\section{REFERENCES}

Agasthialingam, S. \& Karunakaran, K. 1980. Sociolinguistics and dialectology, All India Tamil Linguistics Association, Annamalainagar.

Bell, R.T. 1976. Sociolinguistics-Goals approaches and problems. B.T Batstord Ltd: London.

Bright, W. 1968 Social Dialect and Semantic Structure in South Asia. Structure and change in Indian Society. Singer, M., Cohn.B. (Eds) New York.WGFAR.

Crystal, D. 1985 A dictionary of linguistics as phonetics. Basil Blackwell Ltd: London.

Fishman, J.A. 1971. Reading in Sociology of Language. Mouton \& Co: The Hague.

Gnanasundram, V. 1982. Conditions for the Code Mixing behaniou. Third International conference on South Asian Languages and Linguistics.

Hudson, R.A. 1980. Sociolinguistics. Cambridge University Press, London.

Karunakaran, K. \& Shivashanmugam, C. 1978. Studies in Tamil Socio-linguistics Malar Pathippakam: Annamalai Nagar.

Karunakaran, K. 1983. Sociolinguistic Pattern of Language Use. Malar Pathippagam, Annamalainagar.

Karunakaran, K. 1981. Study of Social dialect in Tamil, Malarpathippagam,Annamalainagar.

Labov, W. 1966. The Social Stratification of English in New York City, Washington D.C.: CAL.
Richard, T.C. (et al.). 1985. Longman Dictionary of Applied Linguistics. Longman: London.

Trudgill, P. 1974. Sociolinguistics - An Introduction, Oxford University Press: London.

Wardhaph, R. 1986. An introduction to sociolinguistics. Blackwell Publishers Ltd: London.

Koslow, Scott, Prem Shamdasani, and Ellen Touchstone (1994), "Exploring Language Effects in Ethnic Advertising: A Sociolinguistic Perspective," Journal of Consumer Research, 20 (March), 575-585.

Luna, David and Laura Peracchio (2002), "Where There Is A Wil!...": Motivation As A Moderator Of Language Processing By Bilingual Consumers," Psychology and Marketing, 19 (7-8), 573-594.

Luna, David and Laura A. Peracchio (2001), "Moderators of Language Effects in Advertising to Bilinguals: A Psycholinguistic Approach." Journal of Consumer Research, 28 (September) 284-295.

Myers-Scotton, Carol (1993a), Social Motivations for Codeswitching: Evidence from Africa. Oxford and New York: Oxford University Press.

Myers-Scotton, Carol (1993b), "Common and Uncommon Ground: Social and Structural Factors in Codeswitching," Language in Society, 22 (4), 475-503. 